\title{
Right anterior minithoracotomy versus conventional aortic valve replacement: A propensity score matched study
}

\author{
Mattia Glauber, MD, Antonio Miceli, MD, PhD, Daniyar Gilmanov, MD, Matteo Ferrarini, MD, \\ Stefano Bevilacqua, MD, Pier A. Farneti, MD, and Marco Solinas, MD
}

\begin{abstract}
Objective: Minimally invasive aortic valve surgery by way of a right anterior minithoracotomy has shown excellent results in terms of mortality, morbidities, and patient satisfaction. The aim of the present study was to compare minimally invasive aortic valve surgery by way of a right anterior minithoracotomy with conventional full sternotomy on early outcomes and midterm survival.
\end{abstract}

\begin{abstract}
Methods: A retrospective, observational, cohort study was undertaken of prospectively collected data from 637 consecutive patients undergoing isolated aortic valve surgery from January 2005 to July 2010. Of the 637 patients, $192(30 \%)$ underwent minimally invasive aortic valve surgery by way of a right anterior minithoracotomy. Of these, 138 patients (right anterior minithoracotomy group) were matched to a control group (full sternotomy group) using propensity score analysis.
\end{abstract}

Results: The baseline characteristics were similar in both groups. The overall in-hospital mortality was $0.7 \%$ (2/276), with no difference between the 2 groups. Minimally invasive aortic valve surgery by way of a right anterior minithoracotomy was associated with a lower incidence of postoperative atrial fibrillation $(25[18.1 \%]$ vs $41[29.7 \%] ; P=.003)$ and blood transfusions (26 [18.8\%] vs $47[34.1 \%] ; P=.0006)$. In addition, patients in the right anterior minithoracotomy group had a shorter mechanical ventilation time (median, 6 vs 8 hours; $P=.004$ ) and postoperative length of stay (median, 5 vs 6 days; $P=.02$ ). The occurrence of stroke, renal failure, reexploration for bleeding, and wound infection was similar in both groups. At a median follow-up of 30 months (range, $17-54$ months), survival was $96 \% \pm 2 \%$ vs $88 \% \pm 4 \%(P=.3)$.

Conclusions: Right anterior minithoracotomy in patients undergoing isolated aortic valve surgery is associated with a lower incidence of postoperative atrial fibrillation and blood transfusion and shorter ventilation time and hospital length of stay. Prospective randomized trials are needed to confirm our data. (J Thorac Cardiovasc Surg 2013;145:1222-6)

Aortic valve replacement (AVR) by way of a full sternotomy (FS) is the conventional standard approach in the treatment of aortic valve disease. ${ }^{1}$ The clinical outcomes after AVR have improved dramatically in the past decade despite gradual increases in patient age and overall risk profile. Recent data reported from the Society of Thoracic Surgeons database showed an overall operative mortality and stroke rate for isolated AVR of $2.6 \%$ and $1.4 \%$, respectively. ${ }^{2,3}$ Despite these excellent outcomes, several minimally invasive techniques have recently been developed as alternative to FS to reduce the "invasiveness" of the surgical procedure, while maintaining the same quality and safety of the standard AVR approach. ${ }^{4}$

According to a recent scientific statement from the America Heart Association, the term "minimally invasive" refers to a small chest wall incision that does not include a FS. ${ }^{5}$ The

From the Department of Cardiothoracic Surgery, Fondazione G. Monasterio CNR-Regione Toscana, Massa, Italy.

Disclosures: Authors have nothing to disclose with regard to commercial support.

Received for publication Nov 18, 2011; revisions received Feb 20, 2012; accepted for publication March 22, 2012; available ahead of print April 20, 2012

Address for reprints: Antonio Miceli, MD, PhD, Fondazione G. Monasterio CNR-

Regione Toscana, Massa 54100, Italy (E-mail: antoniomiceli79@alice.it).

0022-5223/\$36.00

Copyright (c) 2013 by The American Association for Thoracic Surgery

doi:10.1016/j.jtcvs.2012.03.064 most common minimally invasive approach is the upper ministernotomy. Other less-invasive techniques include a right parasternal approach from the second to the fourth costal cartilages, transverse sternotomy, and right anterior minithoracotomy (RT). Compared with conventional surgery, minimally invasive AVR has been shown to reduce postoperative mortality, morbidity, and pain while providing faster recovery, a shorter hospital stay, and better cosmetic results. ${ }^{4,7-10}$ However, data reported from most of these studies have focused mainly on upper ministernotomy; few studies have described the outcomes associated with minimally invasive AVR using a RT. Previously, we reported our experience with minimally invasive AVR using a RT and showed excellent surgical results in terms of mortality, morbidities, and patient satisfaction. ${ }^{11}$ Nevertheless, comparative studies between RT and FS on postoperative outcomes have not been well described. Therefore, the aim of our study was to compare AVR by way of a RT with conventional FS on early outcomes and midterm survival using a propensity matching method.

\section{METHODS}

This was a retrospective, observational, cohort study of prospectively collected data from 637 consecutive patients who underwent isolated 

Abbreviations and Acronyms
AVR $=$ aortic valve replacement
FS $=$ full sternotomy
RT $=$ right anterior minithoracotomy
TAVI $=$ transcatheter aortic valve implantation

AVR at our institution from January 2005 to June 2010. The local ethical committee approved the study, and individual consent was waived. The data collection form was entered in a local database and included 3 sections completed consecutively by the cardiac surgeons, anesthetists, and perfusionists involved in the care of the patients. The exclusion criteria were active infective endocarditis, other minimally invasive procedures, including transcatheter aortic valve implantation (TAVI), and a critical preoperative state defined as any 1 or more of the following: ventricular arrhythmia, cardiac massage or aborted sudden death, ventilation before arrival in the anesthetic room, acute renal failure, and inotropic support. Eighteen patients underwent TAVI through a transapical approach. The final sample contained detailed clinical information for 528 patients, of whom 192 patients $(36.5 \%)$ underwent AVR by way of RT. The percentage of patients with aortic stenosis undergoing RT for conventional AVR versus TAVI was $82.8 \%$ versus $3.9 \%$. To reduce the effect of treatment selection bias and potential confounding in the present observational study, we developed a propensity score-matching analysis. Thus, 138 patients undergoing AVR by way of a RT (RT group) were matched to a control group (FS group). In-hospital mortality was defined as any death occurring during the same hospital admission for surgery. Atrial fibrillation (AF) was defined by the documentation of $\mathrm{AF}$ of any duration at any point in the postoperative period on the basis of a rhythm strip or 12-lead electrocardiogram. Finally, stroke was diagnosed if evidence was found of a new neurologic deficit with morphologic substrate confirmed by computed tomography or nuclear magnetic resonance imaging.

\section{Preoperative Planning and Surgical Techniques}

The exclusion criteria for the RT approach were previous cardiac surgery, a history of right-sided pleuritis, and aortic root dilatation. The preoperative planning and surgical techniques have been previously described. ${ }^{11}$ In brief, all patients scheduled for AVR underwent 64-slice computed tomography (Toshiba Aquilon; Toshiba Medical System, Tokyo, Japan) without contrast enhancement to evaluate the anatomic relationship among the intercostal spaces, ascending aorta, and aortic valve. Patients were suitable for RT only if the following criteria were met: (1) at the level of main pulmonary artery, the ascending aorta was rightward (more than one half located on the right in respect to the right sternal border); and (2) the distance from the ascending aorta to the sternum did not exceed $10 \mathrm{~cm}$.

Minimally invasive AVR by way of RT was performed through a 5- to 7-cm skin incision placed at the level of the second or third intercostal space without rib resection. After excluding the right internal thoracic artery with a soft tissue retractor (Estech, San Ramon, Calif, or CardioVation; Edwards Lifesciences, Irvine, Calif), direct aortic cannulation was performed using Easyflow (Estech) or Straightshot (Edwards Lifesciences) cannulas. A variety of percutaneous venous cannulas such as BioMedicus multistages (Medtronic, Minneapolis, Minn), Quickdraw (Edwards Lifesciences), RAP (Estech), or Smartcannula (Smartcannula, Lausanne, Switzerland) were inserted through the femoral vein into the right atrium, and the correct position was achieved with the Seldinger technique under transesophageal echocardiographic guidance. After vacuum-assisted cardiopulmonary bypass $(-40 \mathrm{~mm} \mathrm{Hg}$ to $-60 \mathrm{~mm} \mathrm{Hg}$ ) was established, a left ventricular vent was placed through the right superior pulmonary vein, and the patients were cooled to $34^{\circ} \mathrm{C}$. The ascending aorta was clamped with the Cygnet crossclamp (Novare Surgical Systems, Cupertino, Calif) or with the aortic
Glauber clamp (Cardiomedical GmbH, Langenhagen, Germany; distributed by Sorin, Salluggia, Italy), ${ }^{12}$ and antegrade cardioplegic solution was given into the aortic root or selectively into the coronary ostia using warm blood cardioplegia or cold crystalloid solution (Custodiol Koehler Chemie, Alsbach-Haenlein, Germany). In the control group, conventional AVR was performed using a FS, and cardiopulmonary bypass was instituted with the use of ascending aortic cannulation and 2-stage venous cannulation of the right atrium. The left side of the heart was vented as described for the RT group, and myocardial protection was obtained with combined anterograde and retrograde warm blood cardioplegia solution. In all cases, the surgical field was flooded with carbon dioxide at a flow of $0.5 \mathrm{~L} / \mathrm{min}$.

\section{Statistical Analysis}

Continuous data are expressed as the mean \pm standard deviation and categorical data as percentages. The Kolmogorov-Smirnov test was used to check for the normality of data in the 2 groups before additional analysis. Differences between the 2 groups were compared with the use of a chisquare test for categorical variables and the $t$-test or Wilcoxon rank sum test, as appropriate, for continuous variables. To reduce the effect of selection bias and potential confounding, we developed a propensity score analysis. The propensity for the RT approach was built using a nonparsimonious multiple logistic regression analysis. All the variables listed in Table 1 were included in the analysis. We used 5 to 1 digit matching to identify the matched patients. After the propensity score match was performed, differences between the 2 groups were assessed using the paired $t$ test or Wilcoxon signed rank test for continuous variables and McNemar's test for categorical variables. The results are reported as percentages and odds ratios, with $95 \%$ confidence intervals. All reported $P$ values are 2-sided. Conversions to FS were analyzed as intention to treat. All statistical analysis was performed with SPSS, version 15.0 (SPSS, Chicago, Ill).

\section{RESULTS}

Of the 528 patients in the present study, $192(36.3 \%)$ underwent isolated AVR by way of RT (RT group) and 336 (63.7\%) underwent conventional surgery (control group). The baseline characteristics of the study population are listed in Table 1. Compared with the FS group, the patients in the RT group were younger, had a smaller body surface area, and a lower prevalence of hypertension and female gender. Moreover, patients undergoing RT were more likely to have better New York Heart Association functional class. After performing propensity score analysis for the entire population, 138 patients undergoing AVR by way of RT were matched to the FS group. In the matched cohort, the differences between the RT and control groups in the baseline characteristics were no longer significant (Table 2). The baseline characteristics of the excluded RT patients and their comparison with the RT-matched patients are reported in Appendix Table 1.

The overall in-hospital mortality was $0.7 \%(2 / 276)$, with no difference between the 2 groups $(0.7 \%, 1 / 138$ vs $0.7 \%$, $1 / 138, P=1)$. Patients in the RT group had longer cardiopulmonary bypass $(121.6 \pm 45$ vs $107.1 \pm 32.3, P=.003)$ and crossclamping $(86.9 \pm 31.8$ vs $72.1 \pm 27.2, P<.0001)$ times. Two patients required intraoperative conversion in the RT group (1.5\%), 1 for a paravalvular leak and 1 for severe pleural adhesions. Minimally invasive AVR by way of 
TABLE 1. Baseline patient characteristics

\begin{tabular}{|c|c|c|c|}
\hline Variable & RT $(n=192)$ & FS $(n=336)$ & $P$ value \\
\hline Age (y) & $67 \pm 12$ & $72 \pm 11$ & $<.0001$ \\
\hline Female gender (n) & $59(31)$ & $201(59.8)$ & $<.0001$ \\
\hline BMI $\left(\mathrm{kg} / \mathrm{m}^{2}\right)$ & $1.9 \pm 0.2$ & $1.8 \pm 0.2$ & .001 \\
\hline COPD (n) & $25(13)$ & $65(19.3)$ & .11 \\
\hline Hypertension (n) & $130(68)$ & $283(84.2)$ & $<.0001$ \\
\hline Serum creatinine $(\mathrm{mg} / \mathrm{dL})$ & $1.03 \pm 0.3$ & $1.1 \pm 0.6$ & .7 \\
\hline Diabetes mellitus (n) & $37(19)$ & $59(17.6)$ & .8 \\
\hline NYHA III-IV functional class (n) & $49(26)$ & $121(36)$ & .02 \\
\hline Ejection fraction $(\mathrm{n})$ & $56 \pm 7$ & $55 \pm 10$ & .14 \\
\hline Extracardiac vasculopathy (n) & $20(10.4)$ & $54(16.1)$ & .17 \\
\hline Aortic valve disease (n) & & & .14 \\
\hline Aortic stenosis & $90(47)$ & $166(49.4)$ & \\
\hline Aortic regurgitation & $40(21)$ & $49(16.1)$ & \\
\hline Mixed & $62(32)$ & $121(36)$ & \\
\hline euroSCORE & & & $<.0001$ \\
\hline Median & 5.2 & 7 & \\
\hline Interquartile range & $2.5-8.6$ & $4.9-12$ & \\
\hline
\end{tabular}

RT was associated with a lower incidence of postoperative $\mathrm{AF}(25[18.1 \%]$ vs 41 [29.7\%]; odds ratio, $0.54 ; 95 \%$ confidence interval, $0.3-0.9 ; P=.003$ ) and blood transfusions in the intensive care unit ( $18.8 \%$ vs $34.1 \%$, odds ratio, 0.43 ; $95 \%$ confidence interval, $0.22-0.8 ; P=.0006)$. In addition, patients in RT group had a shorter mechanical ventilation time (median, 6 vs 8 hours; $P=.004$ ) and postoperative length of stay (median, 5 vs 6 days; $P=.02$ ). The incidence of reexploration for bleeding was $4.3 \%$ in the FS group and $6.5 \%$ in the RT group $(P=.6)$. In the RT group, the causes

TABLE 2. Baseline characteristics of propensity-matched patients

\begin{tabular}{lccc}
\hline \multicolumn{1}{c}{ Variable } & RT $(\mathbf{n}=\mathbf{1 3 8})$ & FS $(\mathbf{n}=\mathbf{1 3 8})$ & $\boldsymbol{P}$ value \\
\hline Age (y) & $69.5 \pm 12.4$ & $69.8 \pm 11.6$ & .6 \\
Female gender (n) & $58(42)$ & $54(39.1)$ & .7 \\
BMI $\left(\mathrm{kg} / \mathrm{m}^{2}\right)$ & $1.85 \pm 0.2$ & $1.87 \pm 0.2$ & .3 \\
COPD (n) & $22(15.9)$ & $22(15.9)$ & 1 \\
Hypertension (n) & $110(79.7)$ & $110(79.7)$ & 1 \\
Serum creatinine (mg/dL) & $1.02 \pm 0.6$ & $1.02 \pm 0.3$ & .7 \\
Diabetes mellitus (n) & $27(16.9)$ & $33(23.9)$ & .5 \\
NYHA III-IV functional class (n) & $41(30)$ & $46(33.3)$ & .7 \\
Ejection fraction (n) & $56.5 \pm 9$ & $56.5 \pm 8$ & .8 \\
Extracardiac vasculopathy (n) & $17(12.3)$ & $18(13)$ & 1 \\
Aortic valve disease (n) & & & .9 \\
$\quad$ Aortic stenosis & $61(44.2)$ & $64(46.3)$ & \\
$\quad$ Aortic regurgitation & $27(19.6)$ & $27(19.6)$ & \\
$\quad$ Mixed & $50(36.2)$ & $47(34.8)$ & \\
euroSCORE & & & .2 \\
$\quad$ Median & 5.6 & 5.4 & \\
$\quad$ Interquartile range & $3-8.1$ & $3-7.5$ & \\
\hline
\end{tabular}

Data presented as mean \pm standard deviation or numbers (percentages). $R T$, Right anterior minithoracotomy; FS, full sternotomy; $B M I$, body mass index; $C O P D$, chronic obstructive pulmonary disease; NYHA, New York Heart Association; euroSCORE European System for Cardiac Operative Risk Evaluation. of reexploration for bleeding were medical related to coagulopathy in 5 patients and surgical in 4 patients related to either some vessels in the subcostal soft tissue $(n=2)$ or the suture lines of the aortotomy $(\mathrm{n}=2)$. In the FS group, 4 patients required reexploration for bleeding for coagulopathy and 2 patients for sternal suture sites. A permanent pacemaker was implanted in 1 patient undergoing RT and 2 patients undergoing FS. The occurrence of stroke, renal failure, and wound infection was similar in both groups (Table 3). In the RT group, 2 patients were discharged with a mild paravalvular leak; no paravalvular leaks were observed in the FS group. The postoperative outcomes of the unmatched patients are reported in Appendix Table 2. At a median follow-up of 30 months (interquartile range, $17-54$ months), the survival was $96 \% \pm 2 \%$ vs $88 \% \pm$ $4 \%(P=.3)$ for the RT and FS group, respectively.

\section{DISCUSSION}

Our propensity-matched study shows that minimally invasive AVR using a RT is a safe and reproducible procedure associated with a low incidence of postoperative mortality and morbidity and good midterm survival. Specifically, we found that patients undergoing AVR by way of RT had a lower incidence of postoperative AF and blood transfusions and had a shorter ventilation time and postoperative length of stay compared with those undergoing standard median sternotomy.

Despite the increasing number of elderly patients and patients with significant comorbidities, the mortality and postoperative complications after AVR have improved dramatically in the past decade. ${ }^{2,3}$ However, the development of new technologies and the improvement in surgical and anesthetic techniques have made minimally invasive surgery a safe and efficient treatment option with greater patient satisfaction. ${ }^{4}$

Minimally invasive AVR has been shown to decrease postoperative complications, providing faster recovery,

TABLE 3. Postoperative outcomes

\begin{tabular}{lccc}
\hline \multicolumn{1}{c}{ Outcome } & RT $(\mathbf{n}=\mathbf{1 3 8})$ & FS $(\mathbf{n}=\mathbf{1 3 8})$ & $\boldsymbol{P}$ value \\
\hline Mortality (n) & $1(0.7)$ & $1(0.7)$ & 1 \\
Stroke (n) & $1(0.7)$ & $2(1.5)$ & 1 \\
Reexploration for bleeding (n) & $9(6.5)$ & $6(4.3)$ & .6 \\
New-onset postoperative AF (n) & $25(18.1)$ & $41(27.9)$ & .03 \\
Blood transfusions (n) & $26(18.8)$ & $47(34.1)$ & .006 \\
Wound infection (n) & 0 & $1(0.7)$ & 1 \\
Ventilation time (h) & & & .004 \\
$\quad$ Median & 6 & 8 & \\
$\quad$ Range & $5-9$ & $6-11$ & .02 \\
Hospital stay (d) & & & \\
$\quad$ Median & 5 & 6 & \\
$\quad$ Range & $4-6$ & $5-7$ & \\
\hline Data presian
\end{tabular}

Data presented as numbers (percentages). $R T$, Right anterior minithoracotomy; $F S$, full sternotomy; $A F$, atrial fibrillation. 
a shorter hospital length of stay, less pain, better aesthetic results, and, consequently, less use of hospital resources. ${ }^{6-8,13-16}$ In small randomized studies, Bonacchi and colleagues ${ }^{14}$ and Mächeler and colleagues ${ }^{15}$ reported beneficial effects with minimally invasive AVR on blood transfusions, mechanical ventilation, and hospital stay. Murtuza and colleagues, ${ }^{7}$ in a meta-analysis of 4667 patients undergoing isolated AVR, demonstrated that those receiving any minimally invasive procedure might benefit in terms of perioperative mortality, intensive care unit and hospital stay, and ventilation time, although the crossclamp and cardiopulmonary bypass times were longer. Similarly, Brown and colleagues ${ }^{6}$ have recently confirmed these data. After performing a systematic review and metaanalysis of 26 studies and a total of 4586 patients undergoing either ministernotomy or conventional surgery, Brown and colleagues ${ }^{6}$ concluded that ministernotomy was associated with shorter ventilation times, intensive care unit and hospital stays, and less blood loss within 24 hours. Despite these positive results, the data reported from most of these studies have focused on ministernotomy. Few studies have evaluated the potential advantages of minimally invasive AVR using the RT approach. Several case series have shown excellent results in terms of mortality and postoperative complications, reporting a low incidence of $\mathrm{AF}$, blood transfusion, mechanical ventilation, and postoperative length of stay. ${ }^{11,17,18}$ However, these benefits were not so evident when compared with conventional surgery. In a propensity score matched analysis, Ruttmann and colleagues ${ }^{19}$ found no difference in the postoperative early outcomes, reporting a longer postoperative ventilation time and a trend toward a greater rate of renal insufficiency in patients undergoing RT. However, the lack of benefits of minimally invasive AVR was probably a result of the greater proportion of elderly patients in the matched minimally invasive AVR group. ${ }^{19}$ It is well known that older age is a risk factor for postoperative AF and renal and pulmonary complications. ${ }^{20-22}$ In contrast, Sharony and colleagues, ${ }^{10}$ in a larger and well propensity matched cohort, found that patients undergoing minimally invasive AVR by way of either RT ( $90 \%$ of total) or ministernotomy had a shorter postoperative length of stay and a greater proportion of patients discharged directly home than those receiving conventional sternotomy. Moreover, our study showed that patients in the RT group had earlier extubation and a lower incidence of blood transfusions and new-onset postoperative AF rate. The smaller incision, preservation of the sternum, and integrity of the costal cartilages would reduce the postoperative pain, improving respiratory function and triggering less postoperative AF. Similarly, De Smet and colleagues ${ }^{23}$ found that minimally invasive AVR was associated with a lower incidence of AF after AVR. In addition, the less dissection of other areas would reduce the risk of bleeding and blood transfusions, although we did not find any difference in terms of chest reopening. Reexploration for bleeding was more common than expected in the RT group; however, its incidence ranges from $3 \%$ to $8 \%$ according to others. ${ }^{7} \mathrm{Fi}-$ nally, patients undergoing minimally invasive AVR had longer cardiopulmonary bypass and aortic crossclamp times than those who received full sternotomy. This was a limitation of our approach, suggesting that exposure and implantation of the prosthetic valves are more challenging than the conventional approach. However, we did not found any complications due to the longer operative times, and our results are in line with those from previous studies. ${ }^{6,7}$ The use of sutureless devices will probably reduce the operative times, further facilitating and standardizing this procedure. Because of the outstanding postoperative outcomes related to the minimally invasive approach, the RT technique might be considered an alternative to TAVI for high-risk patients. In a retrospective study, Zierer and colleagues ${ }^{24}$ found similar early mortality and morbidities among patients undergoing TAVI and minimally invasive AVR procedures. The investigators of the Placement of Aortic Transcatheter valves (PARTNER) trial ${ }^{25}$ have shown the noninferiority of transcatheter AVR versus conventional surgery in terms of early mortality and 1-year survival. However, the TAVI procedures were associated with a greater incidence of vascular complications and an increased hazard of embolic stroke and paravalvular leakage. ${ }^{25}$ In our series, no vascular complications occurred, and the lower incidence of postoperative stroke and paravalvular leakage make RT a safe procedure and a potential alternative to the new growing TAVI technology, which has not yet been validated at midterm follow-up. More studies are required to confirm our hypothesis.

Our study had some limitations. It was based on the retrospective analysis of our institutional, observational, prospectively collected database. Propensity score analysis is simply a method for reducing bias in observational studies when randomization to treatment groups is not possible, and the matching was limited by available variables. In addition, another potential source of bias might be the mindset of postoperative care team, who, consciously or not, could treat RT patients differently (fewer transfusions, early extubation and discharge) because of the small incision.

\section{CONCLUSIONS}

RT in patients undergoing isolated AVR reduces the incidence of postoperative AF, the need for blood transfusion, assisted ventilation time, and hospital length of stay. However, prospective randomized trials are required to confirm our data.

\section{References}

1. Bonow RO, Carabello BA, Chatterjee K, de Leon AC Jr, Faxon DP, Freed MD, et al, American College of Cardiology/American Heart Association Task Force on Practice Guidelines. 2008 Focused update incorporated into the ACC/AHA 2006 guidelines for the management of patients with valvular heart disease: 
a report of the American College of Cardiology/American Heart Association Task Force on Practice Guidelines (Writing Committee to revise the 1998 guidelines for the management of patients with valvular heart disease). Endorsed by the Society of Cardiovascular Anesthesiologists, Society for Cardiovascular Angiography and Interventions, and Society of Thoracic Surgeons. J Am Coll Cardiol. 2008;52:e1-142.

2. Brown JM, O'Brien SM, Wu C, Sikora JA, Griffith BP, Gammie JS. Isolated aortic valve replacement in North America comprising 108,687 patients in 10 years: change in risks, valve types, and outcomes in the Society of Thoracic Surgeons National Database. J Thorac Cardiovasc Surg. 2009;137:82-90.

3. Malaisrie SC, McCarthy PM, McGee EC, Lee R, Rigolin VH, Davidson CJ, et al. Contemporary perioperative results of isolated aortic valve replacement for aortic stenosis. Ann Thorac Surg. 2010;89:751-7.

4. Schitto JD, Mokashi SA, Cohn LH. Minimally invasive valve surgery. J Am Coll Cardiol. 2010;56:455-62

5. Rosengart TK, Feldman T, Borger MA, Vassiliades TA, Gillinov M, Hoercher KJ, et al. Percutaneous and minimally invasive valve procedure: a scientific statement from the American Heart Association council on cardiovascular surgery and anaesthesia, council on clinical cardiology, functional genomics and translational biology interdisciplinary working group, and quality of care and outcomes research interdisciplinary working group. Circulation. 2008;117:1750-67.

6. Brown ML, McKellar SH, Sundt TM, Schaff HV. Ministernotomy versus conventional sternotomy for aortic valve replacement: a systematic review and meta-analysis. J Thorac Cardiovascular Surg. 2009;137:670-9.

7. Murtuza B, Pepper JR, Satnbridge RD, Jone C, Rao C, Darzi A, et al. Minimal access aortic valve replacement: is it worth it? Ann Thorac Surg. 2008;85: 1121-31.

8. Tabata M, Umakanthan R, Cohn L, Bolmann RM II, Shekar PS, Chen FY, et al. Early and late outcomes of 1000 minimally invasive aortic valve replacement. Eur J Cardiothorac Surg. 2008;33:537-41.

9. Brinkman WT, Hoffman W, Dewey TM, Culica D, Prince SL, Hebert MA, et al. Aortic valve replacement surgery: comparison of outcomes in matched sternotomy and PORT ACCESS groups. Ann Thorac Surg. 2010;90:131-5.

10. Sharony R, Grossi EA, Saunders PC, Schwartz CF, Ribakove GH, Baumann G, et al. Propensity score analysis of a six year experience with minimally invasive isolated aortic valve replacement. J Heart Valve Dis. 2004;13:887-93.

11. Glauber M, Miceli A, Bevilacqua S, Farneti PA. Minimally invasive aortic valve replacement via right anterior minithoracotomy: early outcomes and mid term follow-up. J Thorac Cardiovasc Surg. 2011;142:1557-9.
12. Glauber M, Karimov JH. A completely detachable aortic clamping instrument for minimally invasive cardiac surgery. Innovations. 2010;5:309-10.

13. Shekar PS, Cohn LH. Minimally invasive aortic valve surgery. In: Cohn LH, ed. Cardiac Surgery in the Adults. 3rd ed. New York: McGraw Hill; 2007. p. 957-64.

14. Bonacchi M, Profti E, Giunti G, Frati G, Sani G. Does ministernotomy improve postoperative outcome in aortic valve operation? A prospective randomized study. Ann Thorac Surg. 2002;73:460-6.

15. Mächeler HE, Bergmann P, Anelli-Monti M, Dacar D, Rehak P, Knez I, et al. Minimally invasive versus conventional aortic valve operation: a prospective study in 120 patients. Ann Thorac Surg. 1999;67:10001-5.

16. Dogan S, Dzemali O, Wimmer-Greinecker G, Derra P, Doss M, Khan MF, et al. Minimally invasive versus conventional aortic valve replacement: a prospective randomized trial. J Heart Valve Dis. 2003;12:76-80.

17. Plass A, Scheffel H, Alkadi H, Kaufmann P, Genoni M, Falk V, et al. Aortic valve replacement through a minimally invasive approach: preoperative planning, surgical technique and outcome. Ann Thorac Surg. 2009;88:1851-6.

18. Glower DD, Teng L, Desai B. Aortic valve replacement through right minithoracotomy in 306 consecutive patients. Innovations. 2010;5:326-30.

19. Ruttmann E, Gilhofer TS, Ulmer H, Chevtchik O, Kocher A, Schistek R, et al. Propensity score-matched analysis of aortic valve replacement by minithoracotomy. J Heart Valve Dis. 2010;19:606-14.

20. The Task Force for the Management of Atrial Fibrillation of the European Society of Cardiology (ESC). Guidelines for the management of atrial fibrillation. Eur Heart J. 2010;31:2369-429.

21. Brown JR, Cochran RP, Leavitt BJ, Dacey LJ, Ross CS, MacKenzie TA, et al, for the Northern New England Cardiovascular Disease Study Group. Multivariable prediction of renal insufficiency developing after cardiac surgery. Circulation. 2007;116(suppl I):I-139-43.

22. Ferguson MK. Preoperative assessment of pulmonary risk. Chest. 1999;115: 58S-63S.

23. De Smet JM, Rondelet B, Jansens JL, Antoine M, De Canniere D, Le Clerc JL. Assessment based on euroSCORE of ministernotomy for aortic valve replacement. Asian Cardiovasc Thorac Ann. 2004;12:53-7.

24. Zierer A, Wimmer-Greinecker G, Martens S, Moritz A, Doss M. Is transapical aortic valve implantation really less invasive than minimally invasive aortic valve replacement? J Thorac Cardiovasc Surg. 2009;138:1067-72.

25. Smith CR, Leon MB, Mack MJ, Miller DC, Moses JW, Svensson LG, et al, for the PARTNER Trial Investigators. Transcatheter versus surgical aortic-valve replacement in high-risk patients. N Engl J Med. 2011;364:2187-98.
APPENDIX TABLE 1. Baseline characteristic of RT patients selected and excluded using propensity score matching

\begin{tabular}{lccc}
\hline \multicolumn{1}{c}{ Variable } & RT $(\mathbf{n}=\mathbf{1 3 8})$ & FS $(\mathbf{n}=\mathbf{5 4})$ & $\boldsymbol{P}$ value \\
\hline Age (y) & $69.5 \pm 12.4$ & $59 \pm 5$ & $<.0001$ \\
Female (n) & $58(42)$ & $1(2)$ & .7 \\
BSA & $1.85 \pm 0.2$ & $1.94 \pm 0.2$ & .006 \\
COPD (n) & $22(15.9)$ & $3(5.5)$ & .09 \\
Hypertension (n) & $110(79.7)$ & $20(37)$ & $<.0001$ \\
Serum creatinine (mg/dL) & $1.02 \pm 0.6$ & $1.04 \pm 0.2$ & .8 \\
Diabetes mellitus (n) & $27(16.9)$ & $10(18.5)$ & 1 \\
NYHA III-IV functional class (n) & $41(30)$ & $8(14.8)$ & .05 \\
Ejection fraction (n) & $56.5 \pm 9$ & $59.5 \pm 4$ & .02 \\
Extracardiac vasculopathy (n) & $17(12.3)$ & $3(5.5)$ & .26 \\
Aortic valve disease (n) & & & .17 \\
$\quad$ Aortic stenosis & $61(44.2)$ & $29(53.7)$ & \\
$\quad$ Aortic regurgitation & $27(19.6)$ & $13(24.1)$ & \\
$\quad$ Mixed & $50(36.2)$ & $12(22.2)$ & \\
\hline Data presenter &
\end{tabular}

Data presented as mean \pm standard deviation or numbers (percentages). $R T$, Right anterior minithoracotomy; $F S$, full sternotomy; $B S A$, body surface area; $C O P D$, chronic obstructive pulmonary disease; NYHA, New York Heart Association.
APPENDIX TABLE 2. Postoperative outcomes between 2 unmatched groups

\begin{tabular}{lccc}
\hline \multicolumn{1}{c}{ Outcome } & RT $(\mathbf{n}=\mathbf{1 9 2})$ & FS $(\mathbf{n}=\mathbf{3 3 6})$ & $\boldsymbol{P}$ value \\
\hline Mortality (n) & $3(1.6)$ & $5(1.5)$ & 1 \\
Stroke (n) & $1(0.5)$ & $5(1.5)$ & .56 \\
Reexploration for bleeding (n) & $12(6.2)$ & $13(4.3)$ & .3 \\
New-onset postoperative AF (n) & $35(18.2)$ & $96(28.5)$ & .01 \\
Blood transfusions (n) & $31(16.1)$ & $102(30.3)$ & $<.0001$ \\
Wound infection (n) & 0 & $3(0.9)$ & .5 \\
CPB (min) & $123 \pm 45$ & $105 \pm 33$ & $<.0001$ \\
Crossclamp time (min) & $89 \pm 32$ & $71 \pm 24$ & $<.0001$ \\
Ventilation time (h) & & & $<.0001$ \\
$\quad$ Median & 6 & 8 & \\
$\quad$ Range & $5-9$ & $6-12$ & \\
Hospital stay (d) & & & .001 \\
$\quad$ Median & 5 & 6 & \\
$\quad$ Range & $4-6$ & $5-7$ & \\
\hline
\end{tabular}

Data presented as mean \pm standard deviation or numbers (percentages). $R T$, Right anterior minithoracotomy; $F S$, full sternotomy; $A F$, atrial fibrillation; $C P B$, cardiopulmonary bypass. 